\title{
Average shear-wave velocity structure of the Kamchatka peninsula from the dispersion of surface waves
}

\author{
N. M. Shapiro ${ }^{1 *}$, A. V. Gorbatov ${ }^{2}$, E. Gordeev ${ }^{3}$, and J. Dominguez ${ }^{1}$ \\ ${ }^{1}$ Instituto de Geofísica, UNAM, Ciudad Universitaria, Coyoacan 04510, Mexico D.F., Mexico \\ ${ }^{2}$ Earthquake Research Institute, University of Tokyo, Japan \\ ${ }^{3}$ Geophysical Service, Academy of Science of Russia, Petropavlovsk-Kamchatski, Russia
}

(Received January 17, 2000; Revised July 20, 2000; Accepted July 27, 2000)

\begin{abstract}
An average shear-wave velocity structure has been estimated for the path between the Kamchatka Isthmus and Petropavlovsk-Kamchatski. It is obtained from the Monte Carlo inversion of the Rayleigh and Love wave group velocity dispersion curves measured using broad-band seismograms of events in Northern Kamchatka recorded by the IRIS station PET in Petropavlovsk-Kamchatski. The Moho interface was found at a depth of $35 \pm 5 \mathrm{~km}$ and the Konrad one at $18 \pm 4 \mathrm{~km}$. An important feature of the found structure is a low velocity in the upper mantle. This result is coherent with the recent and present-day volcanic activity in Kamchatka. Synthetic long period seismograms computed for the obtained structure are in good agreement with observed ones.
\end{abstract}

\section{Introduction}

Kamchatka peninsula is located in the northwestern Pacific Ocean. Its tectonic regime is dominated by the subduction of the Pacific plate under the Eurasian plate. Main morphological structures of the peninsula are two mountain ridges with a northeastern trend (Fig. 1). The Eastern ridge is essentially formed by an active volcanic belt related to the present day subduction of the Pacific plate. The volcanic belt located in the Middle ridge was active at least up to Holocene time (Shapiro et al., 1987). Therefore, almost all the territory of Kamchatka is characterized by recent or present-day volcanism.

Numerous studies of the crustal and upper mantle structure have been provided in Kamchatka. Kuzin (1974), Balesta (1981), and Gorbatov et al. (1997) have studied the structure of the focal zone in the Eastern Kamchatka. Anosov et al. (1978) and Balesta and Gontovaya (1985) have reported $P$-wave velocities measured from refraction and reflection seismic experiments provided in two locations: (1) in Eastern Kamchatka, in the vicinity of Petropavlovsk-Kamchatski; (2) in Central Kamchatka, in the region west of Klucheskoy volcano. Slavina and Fedotov (1974) have studied $P$-wave velocities in the upper mantle using the arrival times of the Pn seismic phase. Tomographic inversions of the travel times of $P$-waves have been provided by Slavina and Pivovarova (1992) and Gorbatov et al. (1999). Most of these studies concern $P$-wave velocities, while the $S$-wave velocity structure of Kamchatka remains almost unknown. However, the knowledge of the $S$-wave velocities is essential: (a) in better

*Center for Imaging the Earth's Interior, University of Colorado at Boulder, Campus Box 390, Boulder, CO 80309, U.S.A.

Copy right (c) The Society of Geomagnetism and Earth, Planetary and Space Sciences (SGEPSS); The Seismological Society of Japan; The Volcanological Society of Japan; The Geodetic Society of Japan; The Japanese Society for Planetary Sciences. understanding of the geodynamic evolution of Kamchatka, (b) in calculation of synthetic seismograms and estimation of the ground motion from future earthquakes, (c) in improvement of earthquake locations, and (d) in estimation of their focal parameters.

Actually, the Kamchatka Geophysiscal Service uses a model essentially based on the study of Kuzin (1974) provided in Eastern Kamchatka. This approach is justified for processing of a major part of earthquakes occurring in the subduction zone. However, the processing of earthquakes originating from the central, western, and northern parts of the peninsula requires a model more adequate for these regions.

In this study, we use a surface wave approach. It allows us to develop an average flat-layer shear-velocity model. Since the selected epicenter-station paths cross almost all the peninsula from the Kamchatka Isthmus to PetropavlovskKamchatski, the model obtained can be considered as a firstapproximation $S$-velocity structure for Kamchatka.

\section{Measurement of Group Velocities}

A very broad band station has been operated by the IRIS consortium and the Geophysical Service of Kamchatka since 1993 in Petropavlovsk-Kamchatski. A description of the station can be found at the IRIS Global Seismological Network web-site. We have used broadband velocity records (BH channel) of four events originated from the region of the Kamchatka Isthmus. Locations of the events are shown in Fig. 1 and listed in Table 1. Since only one broadband station has been available, we did not measured phase velocities. The measurement of the phase velocity using one-station record requires a correction for the source phase. However, the exact information on the source mechanism for all events has not been available.

The group velocity of the fundamental modes of the 


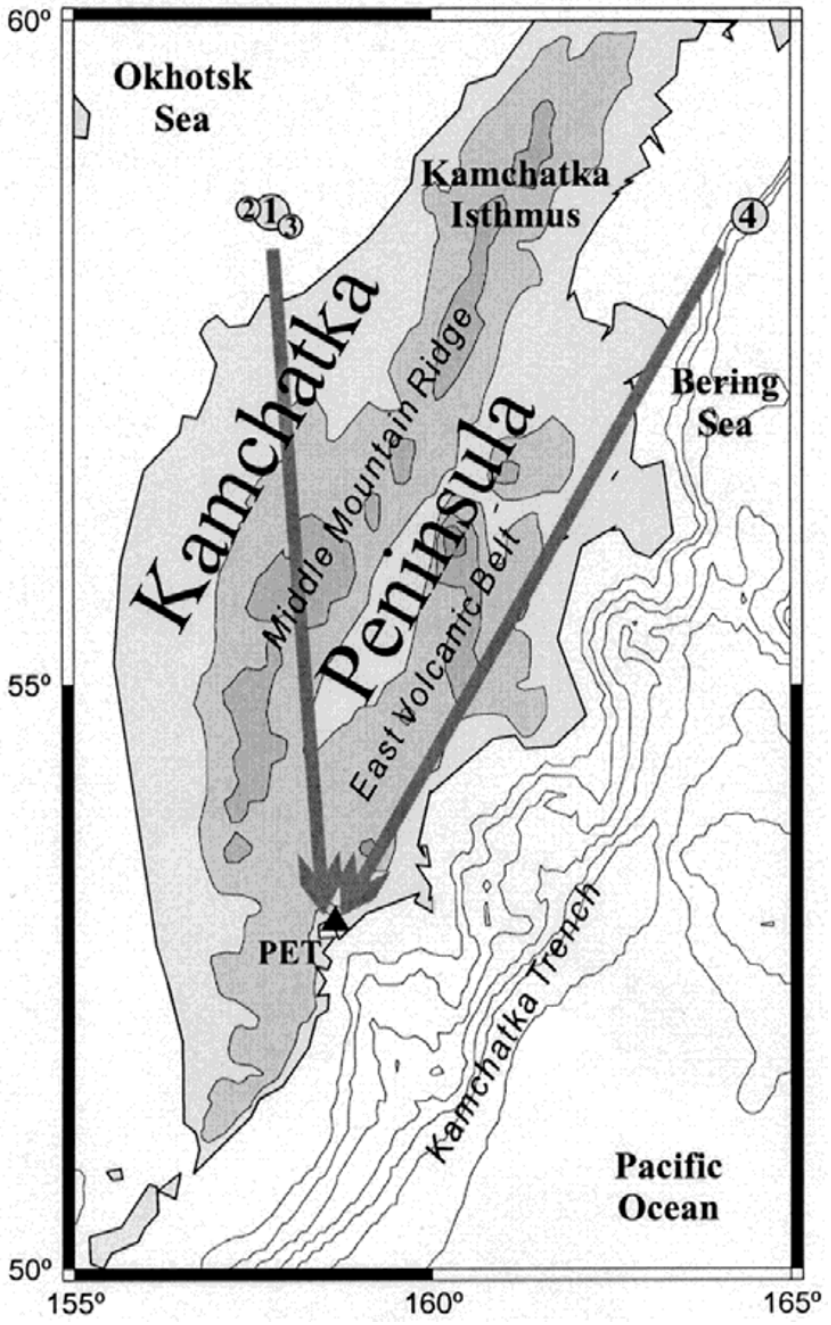

Fig. 1. Topographic map of Kamchatka showing the locations of station PET (triangle) and the four earthquakes used in this study (numbered circles).

Rayleigh and Love waves were measured using a frequencytime analysis (see e.g. Dziewonski et al., 1969, Herrmann, 1987, Levshin et al., 1989). In order to improve the definition of the dispersion curves, we applied the stacking procedure which accumulates the information provided by all available events and provides an average dispersion curve for the region of interest (Campillo et al., 1996; Shapiro et al., 1997). We used the vertical component records of all four events to construct a stacked period-group velocity diagram for the Rayleigh wave and transverse component record of events 1 and 4 for the Love wave diagram. We integrated the velocity records in order to compensate for a strong decrease in the velocity spectra at periods greater than $20 \mathrm{~s}$. Three-component displacement seismograms are presented in Fig. 2. Subsequently, we applied the stacking in the period-group velocity domain.

During the stacking, we corrected systematic errors of the group velocity measurement caused by the decrease of the spectral amplitude at large periods by replacing the central frequency of the filter by the centroid frequency of the filtered spectrum as described by Shapiro and Singh (1999). Resulting period group velocity diagrams are shown in Fig. 3 . We

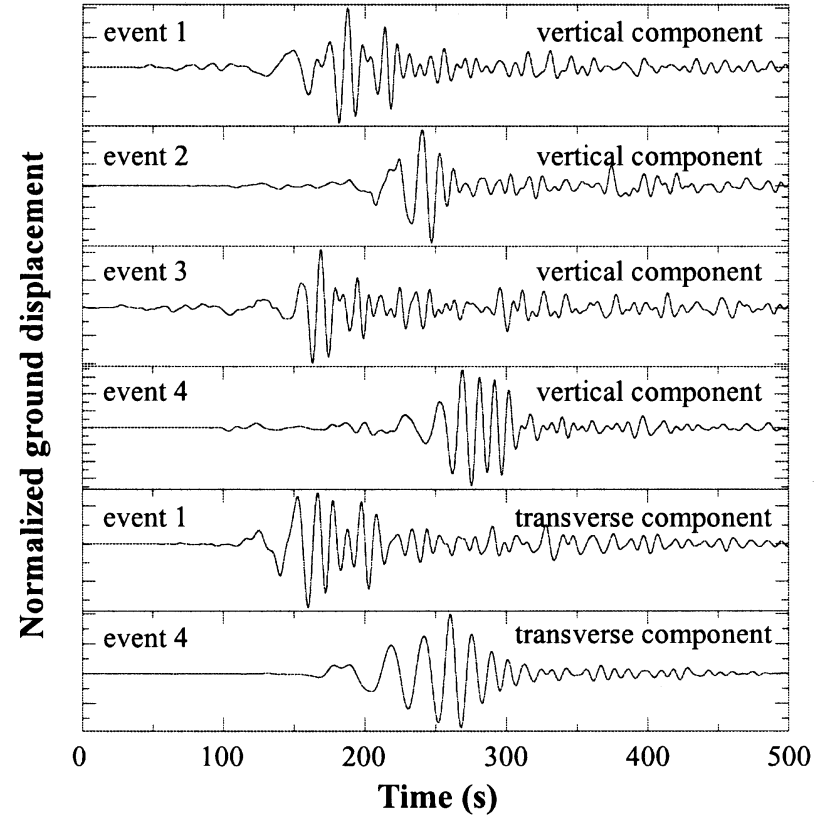

Fig. 2. Three-component ground displacement seismograms recorded at PET. Seismograms are band-passed between 10 and $100 \mathrm{~s}$.

Table 1. Locations and magnitudes of earthquakes used in this study.

\begin{tabular}{ccccccc}
\hline $\mathrm{N}$ & YY.MM.DD & hh:mm:ss & Lat & Lon & $\mathrm{H}(\mathrm{km})$ & $\mathrm{Mb}$ \\
\hline 1 & 96.07 .07 & $10: 59: 00$ & 58.62 & 157.75 & 10 & 5.8 \\
2 & 96.08 .08 & $17: 09: 40$ & 58.64 & 157.56 & 33 & 5.0 \\
3 & 96.09 .13 & $15: 45: 10$ & 58.57 & 157.85 & 33 & 4.9 \\
4 & 98.04 .15 & $15: 23: 07$ & 58.50 & 164.45 & 33 & 5.9 \\
\hline
\end{tabular}

measured group velocities of the Rayleigh wave at periods between 10 and $80 \mathrm{~s}$ (Fig. 3(c)), and of the Love wave at periods between 15 and $80 \mathrm{~s}$ (Fig. 3(d)). At periods larger then 80 $\mathrm{s}$, spectral amplitudes are too small with respect to the noise level. At periods lower then $10 \mathrm{~s}$, signals are strongly affected by multipathing and mode conversion due to small-scale heterogeneities. This mode coupling is enhanced at horizontal components (Stange and Friederich, 1992). Therefore, we could measure Love wave group velocities only at periods greater than $15 \mathrm{~s}$. The uncertainties of the group velocity measurement (shadowed areas in Figs. 3(c) and (d)) were roughly estimated from amplitudes of period-group velocity diagrams (Campillo et al., 1996). Note that the largest uncertainty corresponds to a time error of approximately $10 \mathrm{~s}$. For a shallow earthquake, this error is larger than an error caused by the neglecting of the source group time (Levshin et al., 1999). We have calculated dispersion curves for the fundamental modes of the Love and Rayleigh waves for the model of Kuzin (1974). They are shown with dashed lines in Figs. 3(c) and (d). It can be seen that they are significantly different from the curves measured from the data.

\section{3. $S$-wave Velocity Model}

The measured dispersion curves were inverted to infer the vertical distribution of shear-wave velocities. We applied 
Table 2. Parameters of velocity models used in the numerical simulation.

\begin{tabular}{cccccccc}
\hline \multirow{2}{*}{$\begin{array}{c}\text { Layer } \\
\text { number }\end{array}$} & \multicolumn{3}{c}{ Kuzin $(1974)$} & & \multicolumn{3}{c}{ This study } \\
\cline { 2 - 4 } \cline { 6 - 7 } \cline { 6 - 7 } & $\delta(\mathrm{km})$ & $\mathrm{Vp}(\mathrm{km} / \mathrm{s})$ & $\mathrm{Vs}(\mathrm{km} / \mathrm{s})$ & & $\delta(\mathrm{km})$ & $\mathrm{Vp}(\mathrm{km} / \mathrm{s})$ & $\mathrm{Vs}(\mathrm{km} / \mathrm{s})$ \\
\hline 1 & 5.00 & 4.20 & 2.43 & & 4.62 & 4.25 & 2.46 \\
2 & 10.00 & 5.80 & 3.35 & & 13.84 & 6.11 & 3.53 \\
3 & 20.00 & 6.70 & 3.87 & & 17.97 & 6.61 & 3.82 \\
4 & $\infty$ & 7.80 & 4.51 & & $\infty$ & 7.30 & 4.22 \\
\hline
\end{tabular}
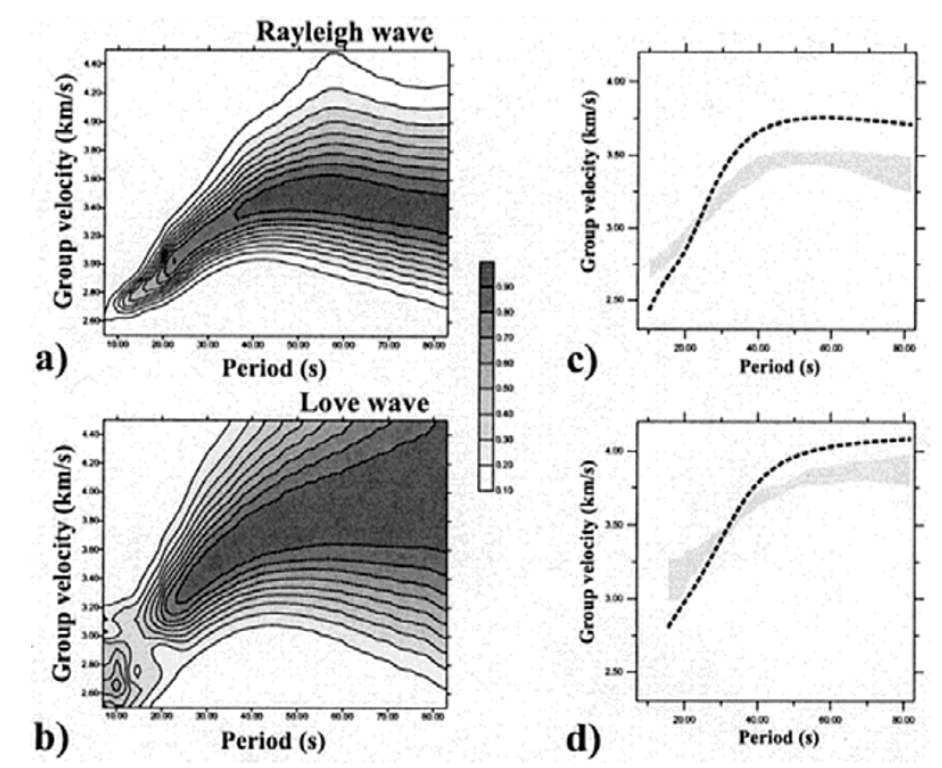

Fig. 3. (a) Stacked period-group velocity diagram for the Rayleigh wave (vertical component records of events 1, 2, 3, and 4). (b) Stacked period-group velocity diagram for the Love wave (transverse component records of events 1 and 4). Corresponding group velocity dispersions of the Rayleigh (c) and Love (d) waves. The shaded areas show average models \pm standard deviation. The dashed lines show the dispersion curves calculated for the model of Kuzin (1974).

a two-step inversion of group velocity dispersion. In the first step the gradient inversion (Herrmann, 1987) has been done. In the second step, following Campillo et al. (1996) and Shapiro et al. (1997), we estimated the uncertainty of the model using a Monte Carlo inversion, i.e. we have provided a random search of models satisfying the observation. Rayleigh and Love wave group velocities have been inverted simultaneously.

The starting model used in our inversion included six layers: three layers in the crust and three layers in the mantle. Layer thickness and velocities were taken from the model of Kuzin (1974). During the inversion, the $S$-wave velocities in the layers and the interface depths were changed, while the Poisson ratio in each layer has been fixed. The results of previous studies of the $P$-wave velocities could not be used as an a-priori information in our inversion, since the most of these studies have been performed in the Eastern Kamchatka or beneath active Volcanoes and cannot be representative for the whole peninsula. Therefore, we have decided to fix the Poisson ratio in each layer (i.e. 1.73).

We have tested more than 20000 models and we have found over 1000 of them satisfying the observations. This set of acceptable models has been used to determine the uncertainty of our inversion. We have calculated average $S$-wave velocities and depths and their standard deviations in each layer. The results of the inversion show that the structure below 70 $\mathrm{km}$ cannot be resolved (i.e. uncertainties are too large) using our data because it request that group velocities be measured at periods longer than $80 \mathrm{~s}$. Therefore, in Fig. 4(a), we only show the results for the upper 70 kilometers. The gray lines show all acceptable models found from the inversion. Dispersion curves corresponding to these models are shown in Fig. 4(b). An average model and its standard deviation are represented by the solid line and the shadowed area in Fig. 4(a). In Table 2, we compare our preferred average model with the one by Kuzin (1974) indicated by the dashed line in Fig. 4(a). While the interface depths are similar for both models, important differences in the velocities are evident. Relative to Kuzin's (1974) model, our model shows higher $S$-wave velocities in the upper crust and lower velocities in the upper mantle.

In Fig. 5, we compare the observed seismograms of event 1 with the reflectivity synthetic seismograms (Kennett, 1985; Randall, 1994) computed for two crustal structures: (a) the model of Kuzin (1974) and (b) the four-layer model represented by the solid line in Fig. 4(a). The value of the seismic 


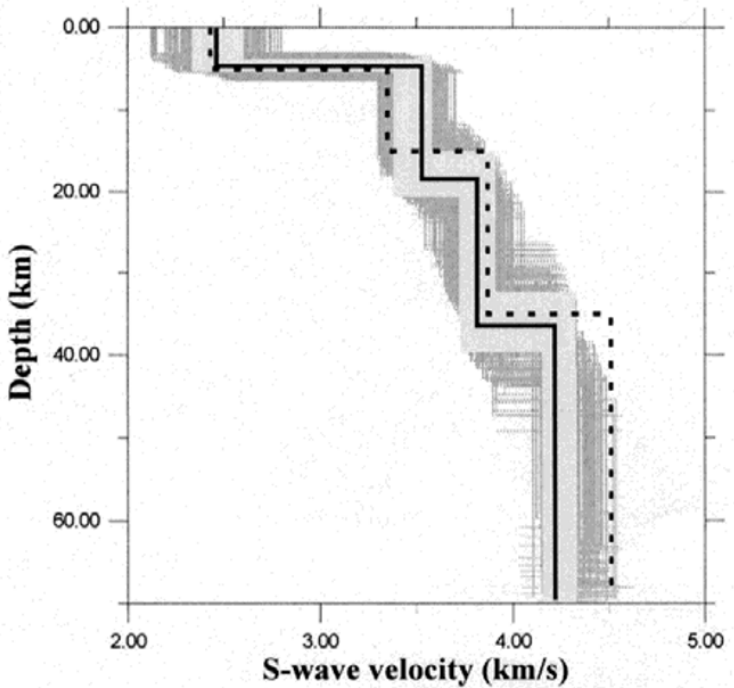

a)

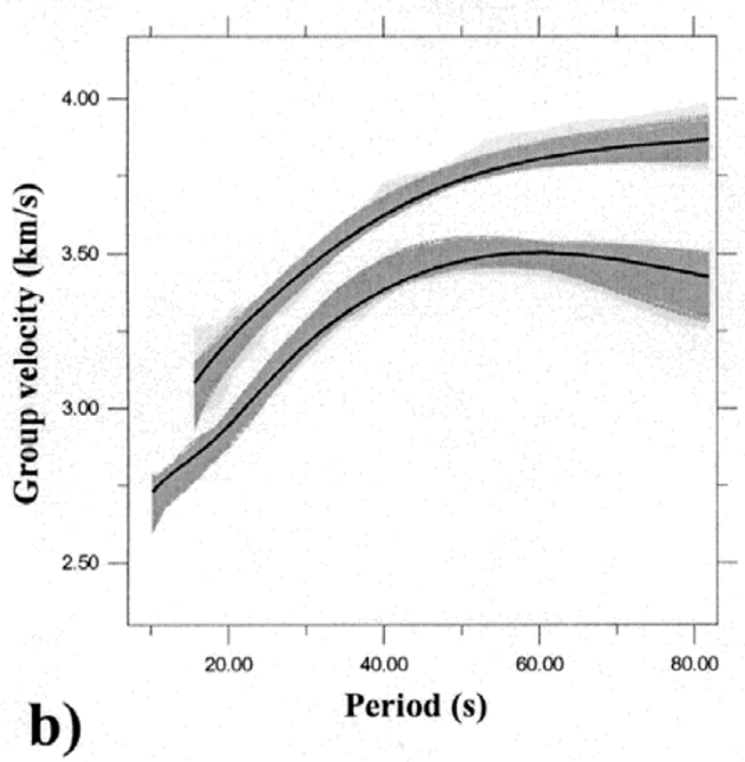

Fig. 4. Results of the Monte Carlo inversion. (a) The gray lines show all the models found. The solid line shows the average model and the shaded area shows its standard deviation. The dashed line shows the model of Kuzin (1974). (b) The shadowed areas show the results of the group velocity measurement. The gray lines show the dispersion curves calculated from the models found. The solid line shows the dispersion curve calculated from the average model.

moment $\left(4.87 \cdot 10^{24} \mathrm{dyn} / \mathrm{cm}\right)$, the source depth $(10 \mathrm{~km})$, and the focal mechanism parameters (strike $329^{\circ}$, Dip $61^{\circ}$, and Rake $35^{\circ}$ ) used in the computation are taken from the Harvard Central Moment Tensor (CMT) catalog. Both the observed and synthetic seismograms have been band-passed between 0.02 and $.05 \mathrm{~Hz}$. It can be seen that the synthetics calculated for the structure determined from the inversion of surface wave dispersion curves fit the observations much better than those calculated for the model of Kuzin (1974). The overall agreement between the observed and synthetic seismograms gives us confidence in the average crustal model found in this study and suggest that it could be used in rapid inversion of moment tensor from the regional seismic records of intraplate earthquakes.



a)

Time (s)

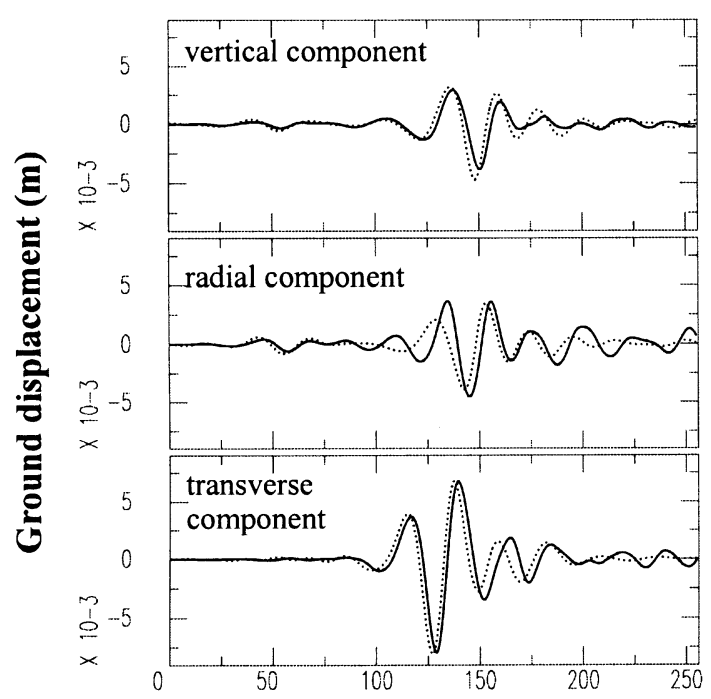

b)

Time (s)

Fig. 5. Comparison of observed (solid lines) and synthetic (dashed lines) seismograms band-passed between 20 and $50 \mathrm{~s}$ and aligned with respect to the first $P$-wave arrival. (a) The model of Kuzin (1974). (b) The model proposed in this study.

\section{Conclusions}

In this study, we have determined an average velocity structure for the region between the Kamchatka Isthmus and Petropavlovsk-Kamchatski based on the inversion of the group velocity dispersion curves of the fundamental modes of the Rayleigh and Love waves. Taking into account the uncertainties of the Monte-Carlo inversion, only velocities at depths less than $70 \mathrm{~km}$ can be constrained. Finally, we propose a four-layer model including: a superficial $5 \mathrm{~km}$ lowvelocity layer, an upper crust, a lower crust, and an upper mantle. A major feature of the found model is the low $S$ wave velocity in the upper mantle. In Table 3, this found velocity is compared with the model presented by Kuzin (1974) and some standard global Earth velocity models like PREM 
Table 3. $S$-wave velocity in the upper mantle for different Earth models.

\begin{tabular}{lc}
\hline Model & Vs $(\mathrm{km} / \mathrm{s})$ \\
\hline This study & 4.22 \\
Kuzin (1974) & 4.51 \\
PREM & 4.49 \\
IASP91 & 4.47 \\
\hline
\end{tabular}

(Dziewonski and Anderson, 1981) and IASP91 (Kennett and Engdahl, 1991). Global and continental scale surface-wave tomographic studies reveals low-velocity anomaly in both phase (Ekström et al., 1997; Curtis et al., 1998) and group (Ritzwoller and Levshin, 1998; Levshin et al., 2000) velocities at relatively long $(\sim 100$ s) periods beneath Kamchatka peninsula. These observations also confirm the presence of the low-velocity material in the upper mantle. More direct observation from a tomographic study has been recently obtained by Levshin et al. (2000). They have found a strong low-velocity anomaly in the propagation of the upper-mantle phases Sn and Pn below Kamchatka. The presence of the low-velocity material in the upper mantle is in agreement with the tectonic regime of the peninsula. The subduction of the Pacific plate below the Eurasian plate results in the recent and present day volcanic activity (Shapiro et al., 1987) and also in high heat flow values throughout the entire territory of Kamchatka (Smirnov and Sugrobov, 1980). Synthetic tests show that the model found in this study gives a good agreement between observed and computed seismograms. In future, with more broadband stations available in the region, it could give a possibility for the determination of the moment tensors of regional earthquakes.

Acknowledgments. We thank Javier Pacheco and Raul Valenzuela for their help in preparation of the manuscript. The broadband seismograms used in this study were provided by the Geophysical Service of Kamchatka and the IRIS Data Management Center.

\section{References}

Anosov, G. I., S. K. Bikkenina, A. A. Popov, K. F. Sergeev, V. K. Utnasin, V. I. Fedorchenko, Deep Seismic Sounding of Kamchatka, 130 pp., Nauka, Moscow, 1978 (in Russian).

Balesta, S. T., The Earth Crust and Magmatic Chambers in Modern Volcanic Regions, 135 pp., Nauka, Moscow, 1981 (in Russian).

Balesta, S. T. and L. I. Gontovaya, The seismic model of the Earth's crust in the Aisatic-Pacific transition zone, Volcanology and Seismology, 4, 83-90, 1985 (in Russian).

Campillo, M., S. K. Singh, N. Shapiro, J. Pacheco, and R. B. Herrmann, Crustal structure south of the Mexican Volcanic Belt, based on group velocity dispersion, Geofis. Int., 35, 361-370, 1996.

Curtis, A., J. Trampert, R. Snieder, B. Dost, Eurasian fundamental mode surface wave phase velocities and their relationship with tectonic structures, J. Geophys. Res., 103, 26919-26947, 1998.

Dziewonski, A. M. and D. L. Anderson, Preliminary reference Earth model,
Phys. Earth Planet. Inter., 25, 297-356, 1981.

Dziewonski, A. M., S. Bloch, and N. Landisman, A technique for the analysis of transient seismic signals, Bull. Seism. Soc. Am., 59, 427-444, 1969.

Ekström, G., J. Tromp, and E. W. F. Larson, Measurements and global models of surface wave propagation, J. Geophys. Res., 102, 8147-8158, 1997.

Gorbatov, A. V., V. Kostoglodov, G. Suarez, and E. Gordeeev, Seismicity and structure of the Kamchatka subduction zone, J. Geophys. Res., 102, 17883-17898, 1997.

Gorbatov, A., J. Dominguez, G. Suarez, V. Kostoglodov, D. Zhao, and E. Gordeev, Tomographic imaging of the P-wave velocity structure beneath the Kamchatka peninsula, Geophys. J. Int., 137, 269-279, 1999.

Herrmann, R. B., Computer Programs in Seismology, Volume IV: Surface Waves Inversion, Saint Luis University, Missouri, 1987.

Kennett, B. L. N., Seismic Wave Propagation in Stratified Media, 342 pp., Cambridge University Press, Cambridge, England, 1985.

Kennett, B. L. N. and E. R. Engdahl, Traveltimes for global earthquake location and phase identification, Geophys. J. Int., 105, 429-465, 1991.

Kuzin, I. P., Focal Zone and the Upper Mantle Structure in the Region of Eastern Kamchatka, 131 pp., Nauka, Moscow, 1974 (in Russian).

Levshin, A. L., T. B. Yanovskaia, A. V. Lander, B. G. Bukchin, M. P. Barmin, L. I. Ratnikova, and E. N. Its, Surface waves in vertically inhomopgeneous media, in Seismic Surface Waves in a Laterally Inhomogeneous Earth, Edited by V. I. Keilis-Borok, pp. 131-182, Kluwer Academic Publisher, Dordrecht, 1989.

Levshin, A. L., M. H. Ritzwoller, and J. S. Resovsky, Source effects on surface wave group travel times and group velocity maps, Phys. Earth Planet. Inter, 115, 293-312, 1999.

Levshin, A. L., M. H. Ritzwoller, M. P. Barmin, A. Villaseñor, and C. A. Padgett, New constrains on the Arctic crust and uppermost mantle: surface wave group velocities, Pn, and Sn, Phys. Earth Planet. Inter. 2000 (in press).

Randall, G. E., Efficient calculation of composite differential seismograms for laterally homogeneous Earth model, Geophys. J. Int., 118, 245-254, 1994.

Ritzwoller, M. H. and A. L. Levshin, Eurasian surface wave tomography: Group velocities, J. Geophys. Res., 103, 4839-4868, 1998.

Shapiro, N. M. and S. K. Singh, A systematic error in estimating surfacewave group-velocity dispersion curves and a procedure for its correction, Bull. Seism. Soc. Am., 89, 1138-1142, 1999.

Shapiro, M. N., V. A. Ermakov, A. E. Shantser, V. I. Shuldiner, A. I. Khanchuk, and S. V. Visotski, Description of the Tectonic Evolution of Kamchatka, Nauka, Moscow, 1987 (in Russian).

Shapiro, N. M., M. Campillo, A. Paul, S. K. Singh, D. Jongmans, and F. J. Sanchez-Sesma, Surface wave propagation across the Mexican Volcanic Belt and origin of the long-period seismic-wave amplification in the Valley of Mexico, Geophys. J. Int., 128, 151-166, 1997.

Slavina, L. B. and S. A. Fedotov, The velocities of compressional waves in the upper mantle beneath Kamchatka, in Seismicity and Earthquake Prediction, Edited by S. A. Fedotov, pp. 188-200, Nauka, Moscow, 1974 (in Russian).

Slavina, L. B. and N. B. Pivovarova, Three-dimensional velocity models of focal zones and refinement of hypocentral parameters, Phys. Earth Planet. Inter, 75, 77-78, 1992.

Smirnov, Y. B. and V. M. Sugrobov, Earth hit flow in Kuril-Kamchatka and Aleutian provinces, Volcanology and Seismology, 2, 3-18, 1980 (in Russian).

Stange, S. and W. Friederich, Guided wave propagation across sharp lateral heterogeneities: the complete wavefield at a cylindrical inclusion, Geophys. J. Int., 11, 470-482, 1992.

N. M. Shapiro (e-mail: nshapiro@anquetil.colorado.edu), A. V. Gorbatov, E. Gordeev, and J. Dominguez 